\title{
Variações morfológicas espaço-temporais entre as praias de Cibratel e Itanhaém-Suarão, Estado de São Paulo
}

\author{
(Spatial and temporal morphological variations between \\ Cibratel and Itanhaém-Suarão beaches, São Paulo State)
}

\author{
Samara Cazzoli y Goya* \& Moysés Gonsalez Tessler \\ Instituto Oceanográfico da Universidade de São Paulo \\ (Caixa Postal 66149, 05315-970 São Paulo, SP, Brasil) \\ *e-mail: samara@sti.com.br
}

- Abstract: The main morphological difference between Cibratel and Itanhaém Suarão beaches is due to the presence of the Itanhaém river mouth in the second one. Eight monthly beach profiles were done during fourteen months. Simultaneously sediments were sampled in the shoreface and incident waves characteristics were visually estimated. Sediment sampling and bathymetry were done in the adjacent submerged area. The results show that, despite of the predominance of the action from the Tropical South Atlantic Anticyclone (TSAA) over the wave regime, the sedimentation process dynamics from the beaches was mainly controlled by the incidence of frontal systems, leading to a more effective northeastward longshore transport. Aerial photographs and beach sediment characteristics confirm such tendency. At Cibratel beach, the southwestward transport caused by TSAA was more evident than in Itanhaém - Suarão beach. Modifications in the beach dynamics, caused by the presence of the Itanhaém river mouth occurred only in restricted areas of its vicinities.

- Resumo: As praias de Cibratel e Itanhaém-Suarão tem como fator diferencial a presença da desembocadura do Rio Itanhaém na Praia Itanhaém-Suarão. Os trabalhos realizados consistiram na realização mensal de 8 perfis praiais durante um período de 14 meses. Concomitantemente, houve coletas de sedimentos da face praial e observações visuais dos trens de ondas incidentes. Atividades complementares como fotointerpretação; caracterizações climáticas, batimétricas e dos sedimentos de superfície de fundo da zona submersa até 8 metros de profundidade também foram realizadas. Os resultados obtidos demonstraram que, apesar do predomínio da ação do Anticiclone Tropical do Atlântico Sul (ATAS), a dinâmica sedimentar de ambas as praias esteve controlada principalmente pela incidência de sistemas frontais que resultou em um transporte mais efetivo rumo NE. O estudo das fotografias aéreas e a análise dos sedimentos praiais confirmaram uma maior efetividade da deriva litorânea neste rumo. Na Praia de Cibratel, a ação da ATAS foi mais notória que na de Itanhaém-Suarão, causando em ambas a ação da deriva longitudinal rumo SW. A desembocadura fluvial do Rio Itanhaém exerceu influência somente em trechos praiais mais próximos a ela, alterando os mecanismos de transporte litorâneo.

- Descriptors: Beach morphodynamic, Frontal systems, Swell.

- Descritores: Morfodinâmica praial, Sistemas frontais. 


\section{Introdução}

As praias são ambientes sedimentares acumulados por ação das ondas, representando um importante elemento de proteção do litoral.

$\mathrm{O}$ conceito de ambiente praial mais amplamente utilizado foi estabelecido por King (1972) e diz que "as praias são ambientes sedimentares costeiros, formados, mais comumente, por areias de constituição variada, estendendo-se desde onde principia a interferência da velocidade orbital das ondas sobre o fundo marinho, até o limite mais continental da ação das ondas de tempestade ou mudanças fisiográficas bruscas". Os ambientes praiais representam, assim, a zona de transição entre a ação dos processos marinhos. e continentais, estando sujeitos a variações temporais tanto do nível do mar quanto do suprimento sedimentar.

Apesar de sua importância, as praias têm sido um dos ambientes costeiros menos estudados ao longo de todo o mundo. No Brasil, as praias passaram a ter maior freqüência de estudos na década de 90 e apesar do aumento de pesquisas efetuadas, muitas questões estão ainda por serem resolvidas ao longo de toda a costa.

Este trabalho tem como objetivo o estudo de duas praias (Itanhaém-Suarão e Cibratel) para a compreensão da dinâmica sedimentar marinha atual nestes segmentos sendo que estas praias foram escolhidas por serem representativas da porção centro-sul do litoral paulista. A terminologia referente aos setores praiais utilizada neste trabalho segue aquela proposta por Tessler \& Mahiques (2000) (Fig. 1).
As praias de Itanhaém-Suarão e Cibratel estão inseridas na Planície Costeira de Itanhaém (Fig. 2), definida por Suguio \& Martin (1978), sendo separadas entre si por afloramentos do Embasamento Cristalino.

Ambas as praias são retilíneas e possuem a mesma orientação de linha de costa $\left(\mathrm{N} 50^{\circ} \mathrm{E}\right)$, apresentando aumento de largura e diminuição da declividade em direção nordeste. Apesar das várias características em comum, as praias diferenciam-se quanto ao aporte de drenagens, sobretudo devido à presença da foz do Rio Itanhaém (que constitui a segunda maior drenagem do litoral paulista) na praia de Itanhaém-Suarão. A praia de Cibratel apresenta apenas contribuições de rios de pequeno porte (oriundos do afloramento do lençol freático) como é o caso do Rio Piaçaguera.

Essas praias estão expostas ao oceano, sem obstáculos intervindo na ação de ondas, exceto na Praia de Cibratel onde aflora uma laje rochosa a 500 metros mar adentro, nas proximidades da foz do Rio Piaçaguera. Essa laje é denominada localmente de Pedra dos Jesuítas (Fig. 2).

Em termos meteorológicos, a área é marcada pela atuação alternadả de massas de ar tropical oriundas do Anticiclone Tropical Atlântico (ATAS) que origina ondas do quadrante NE - E, e massas de ar polar originadas no Anticiclone Polàr Migratório Atlântico (APM), que origina ondas dos quadrantes $\mathrm{SE}-\mathrm{S}$ - SW. Estas massas de ar sofrem freqüentes perturbações oriundas de sistemas frontais sob a forma de frentes frias, quentes e estacionárias, além de fenômenos localizados como a formação de centros de baixa pressão (Sant'Anna Neto, 1990). Estas perturbações trazem modificações na precipitação pluviométrica.

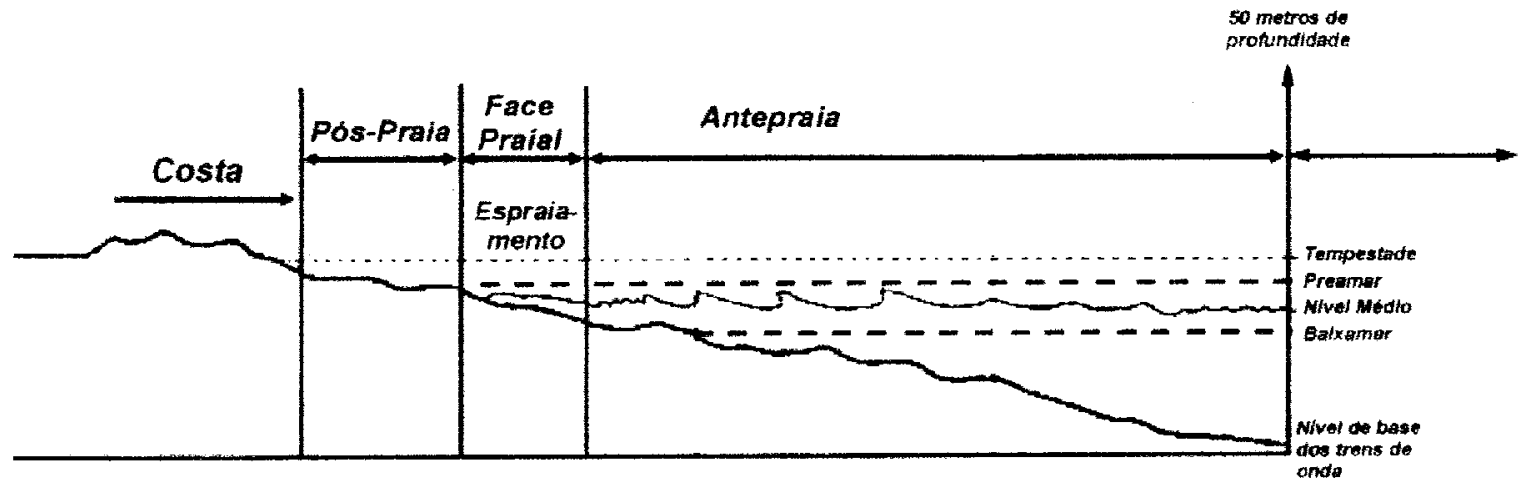

Fig. 1. Terminologia de setores de praia (Tessler \& Mahiques, 2000). 


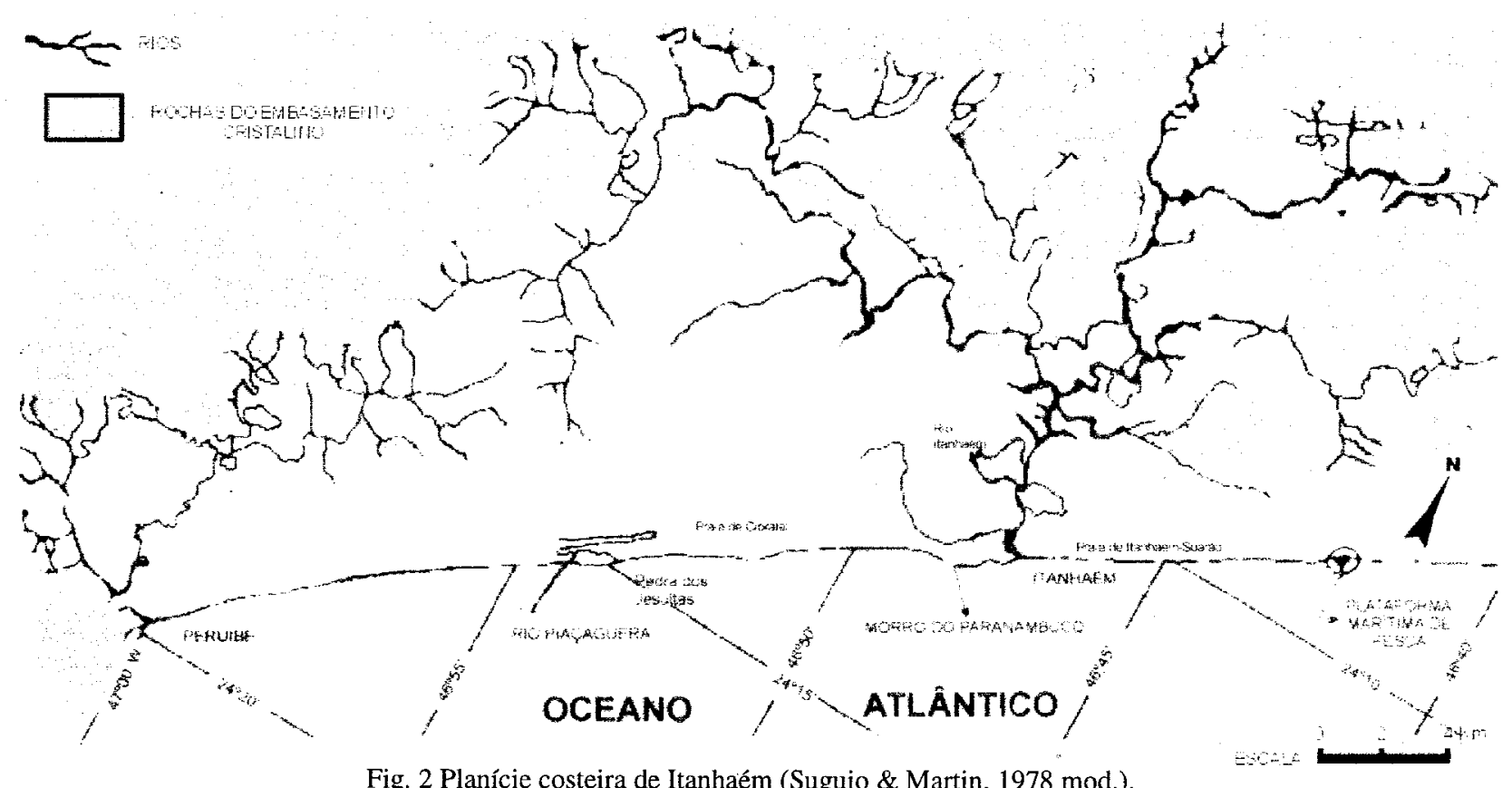

Fig. 2 Planície costeira de Itanhaém (Suguio \& Martin, 1978 mod.).

A área de estudo apresenta, também, um antigo histórico de ocupação humana, mais intensificada a partir da década de 50 , com o início dos loteamentos para veranistas. Esta ocupação trouxe consigo atividades como a extração de areia da face praial e das dunas e, ocupação da pós-praia com construções, loteamentos, arruamentos e aterros, que comprometem a qualidade ambiental da região e sobretudo o balanço sedimentar local.

\section{Material e métodos}

Foram efetuados monitoramentos envolvendo a caracterização da morfodinâmica das praias e a observação das condições sedimentológicas, oceanográficas e meteorológicas. A antepraia foi estudada através de análise de sua batimetria e dos sedimentos de superfície de fundo até a isóbata de 8 metros.

A caracterização das condições morfodinâmicas das praias foi efetuada através do levantamento dos perfis transversais às praias realizado, mensalmente, em maré de sizígia, durante um período de quatorze meses (abril/94 a maio/95). A metodologia aplicada foi aquela descrita por Muehe (1996) com o uso de teodolito e estádia.

As cotas foram, em geral, obtidas a cada dez metros, a partir de um ponto preestabelecido, até atingir a linha d'água. A depender da extensão do perfil, as cotas foram alteradas. Quando a declividade e o nível de maré permitiram, a medição dos perfis ultrapassou a linha d'água, atingindo a zona de antepraia.
De acordo com os levantamentos prévios, foram posicionados 8 perfis sendo que 3 destes (P11, P10 e P9) estavam na Praia de Cibratel e 5 perfis (P8, P7, P6, P5 e P4) na Praia Itanhaém-Suarão. Os marcos de referência escolhidos foram pontos fixos existentes nas imediações, devidamente posicionados por GPS. A Figura 3 apresenta o posicionamento dos marcos iniciais dos perfis topográficos em relação às coordenadas geográficas.

As mudanças verticais dos perfis praiais foram obtidas a partir da sobreposição dos mesmos em meses subseqüentes. A partir desta sobreposição foi também obtida a variação vertical (acresção/erosão) da face praial nestas praias.

A metodologia para monitoramento da configuração da margem da desembocadura do Rio Piaçaguera foi baseada nos mesmos princípios utilizados para o levantamento dos perfis praiais, com o acompanhamento mensal da margem direita do rio. Este monitoramento foi realizado concomitantemente ao levantamento topográfico de praia, tendo como referência o ponto inicial do perfil P11.

O acompanhamento da evolução da desembocadura de um rio de planície costeira implicou em monitorar e entender o conjunto de variáveis que condicionaram seu deslocamento lateral e regime de vazão. Na tentativa de minimizar os erros introduzidos pela comparação entre os períodos de medição, os levantamentos foram executados em fases coincidentes de maré.

Juntamente com a realização dos perfis de praia, foram coletadas, de maneira sistemática, 
amostras dos sedimentos superficiais presentes ao longo dos perfis para a caracterização sedimentológica de ambas as praias.

A coleta das amostras foi feita, geralmente, em três posições distintas nos perfis. A primeira foi coletada no limite da linha de vegetação permanente (quando existente) ou no limite da praia com a urbanização; a segunda na porção central da face praial; e a terceira junto à linha d'água, resultando em um total de 256 amostras. Em laboratório, estas amostras foram estudadas quanto ao teor de carbonato biodetrítico (Gross, 1971), granulometria (Suguio, 1973), morfoscopia (Mahiques, 1987) e composição mineralógica.

Em todo o período de levantamento de campo, foram realizadas medições visuais de dados oceanográficos tais como altura e direção de ondas incidentes em relação à linha de costa. A medição do período das ondas foi realizado com o auxílio de um cronômetro para marcação do intervalo de tempo da passagem de 11 cristas de ondas consecutivas.

Em relação à zona submersa, a caracterização morfológica foi obtida através da confecção de um mapa batimétrico a partir da Folha de Bordo "Peruíbe - Ilha da Moela" (FB-1700004/82) em escala 1:100.000 fornecida pela Diretoria de Hidrografia e Navegação do Ministério da Marinha - DHN/MM (1982), que é a única a abranger a área monitorada. Os sedimentos foram coletados em uma malha pré-definida de 38 estações (Fig. 3) com um amostrador do tipo Petersen modificado. O tratamento em laboratório foi similar ao efetuado para as amostras de sedimentos coletados na área emersa.

Para obtenção dos dados meteorológicos, foram consultados os boletins da Climanálise $(94,95)$, as cartas sinópticas da DHN/MM $(94,95)$, os dados do posto pluviométrico do Departamento de Águas e Esgotos, em Itanhaém (DAEE/SRHSO, 1998) e ainda os dados de pressão atmosférica da base sul do IOUSP, em Cananéia (IOUSP, 1994, 1995).

\section{Resultados}

Os levantamentos dos perfis de praia ocorreram sob distintas condições meteorológicas, abrangendo a atuação de sistemas frontais (sendo estes últimos em condições de pré passagem, pós passagem e sob ação frontal na área) e a ação do ATAS. As Tabelas 1 e 2 mostram resumidamente os resultados obtidos durante as etapas de campo.

Durante a maior parte do monitoramento, as praias estiveram submetidas à vigência do ATAS como verificado nos levantamentos efetuados nos meses de abril, julho, setembro, novembro e dezembro de 1994 e janeiro a maio de 1995.
A ação do ATAS pode ser caracterizada por valores estáveis de temperatura e pressão, comumente mais altos do que a média mensal destes parâmetros. Porém, devido ao longo tempo de monitoramento, as características de atuação do ATAS não foram exatamente as mesmas, com diferentes valores de pressão, temperatura $\mathrm{e}$ pluviosidade. Os valores de temperatura oscilaram entre $18^{\circ} \mathrm{C}$ (julho/94) e $28^{\circ} \mathrm{C}$ (janeiro/95) sendo que a temperatura média de $25^{\circ} \mathrm{C}$ ao longo de todo o período. A pressão atmosférica apresentou o menor valor em janeiro/95 $(757,7 \mathrm{mmHg})$ e o maior valor em julho/94 $(764,51 \mathrm{mmHg})$. Os valores de pressão nos demais períodos monitorados de ATAS ficaram em torno de $760 \mathrm{mmHg}$.

A pluviosidade foi bastante variável, originada por linhas de instabilidade locais, de origem marinha ou continental, gerando pancadas de chuvas rápidas, por vezes de forte intensidade, com menos de duas horas de duração. O registro pluviométrico indicou menores valores acumulados de chuva entre os levantamentos de junho - julho/94 $(50 \mathrm{~mm})$ e outubro - novembro/94 $(30 \mathrm{~mm})$ e acúmulos pluviométricos máximos de $360 \mathrm{~mm}$ entre os de janeiro - fevereiro/95 seguido dos períodos entre dezembro/94 - janeiro/95 e fevereiro - março/95, com $250 \mathrm{~mm}$. De uma maneira geral, houve um déficit de chuva em relação à curvas normais de pluviosidade exceto entre os monitoramentos de fevereiro - março/95.

A direção do vento, monitorada durante a realização das etapas de campo, foi predominantemente dos quadrantes NE/ENE/E e secundariamente do rumo NW. Sob este regime de ventos, as ondas incidiram nas praias provenientes do quadrante $\mathrm{NE}$, com altura significativa de 0.5 metro e período médio de 8 segundos.

$\mathrm{O}$ único caso em que foi monitorada uma praia em condições típicas de pré-frontal foi em janeiro/95, na Praia Itanhaém-Suarão, cerca de 1 dia antes da passagem de um sistema frontal originado no APM. Este sistema frontal caracterizou-se por apresentar rápido deslocamento, indo de Florianópolis a Ubatuba no mesmo dia (20/01/95).

A ação pré-frontal atuante no dia do monitoramento não apresentou queda expressiva dos elevados valores de temperatura (no dia anterior era de $28^{\circ} \mathrm{C}$ e no dia do monitoramento era de $26^{\circ} \mathrm{C}$ ) e da pressão atmosférica (no dia 18/01 a pressão foi medida em $760 \mathrm{mmHg}$ e no dia 19/01 o valor foi de $759,6 \mathrm{mmHg}$ ). Não houve precipitação pluviométrica no dia, embora tenha havido nebulosidade. $O$ vento predominante incidia do quadrante E/ESE/S. Sob estas condições meteorológicas as ondas eram oriundas de SSE, com amplitude de 1 metro e período de 7,9 segundos. 


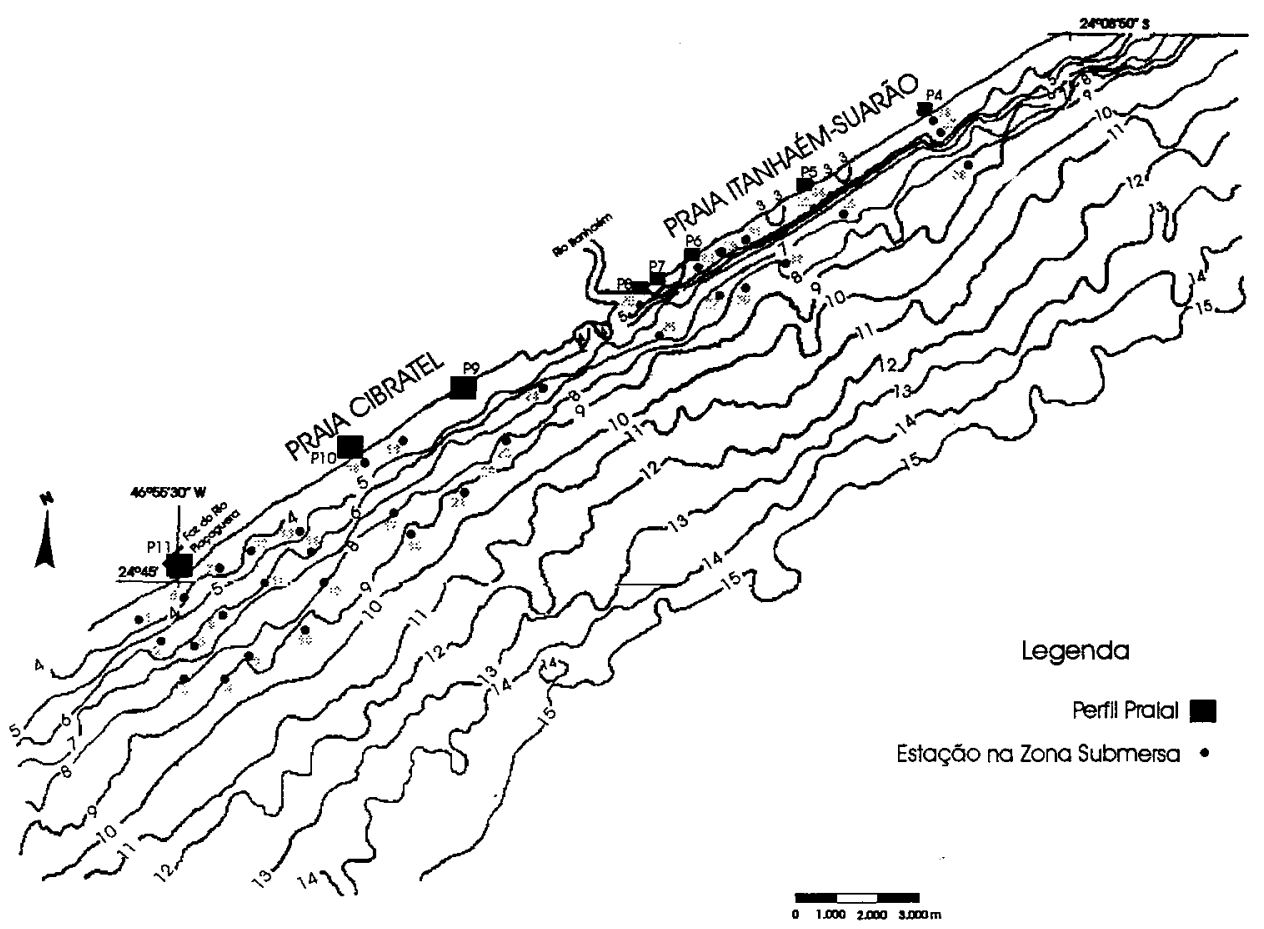

Fig. 3. Mapa de localização dos perfis praiais e das estações na zona submersa.

Tabela 1. Dados sobre o domínio meteorológico vigente em cada monitoramento praial e as datas de passagem de sistemas frontais na área de estudo (abril/94 a maio/95) segundo Boletim Climanálise (1994, 1995).

\begin{tabular}{|c|c|c|}
\hline $\begin{array}{c}\text { Etapa e data } \\
\text { do monitoramento }\end{array}$ & $\begin{array}{c}\text { Domínio meteorológico no } \\
\text { monitoramento }\end{array}$ & Número e datas de sistemas frontais \\
\hline $\begin{array}{l}\text { Abril/94 } \\
27-28 / 04 / 94\end{array}$ & ATAS & $\begin{array}{c}4 \\
(7,10-11,18 \text { e } 22 / 04 / 94)\end{array}$ \\
\hline $\begin{array}{l}\text { Maio/94 } \\
218 / 05 / 94\end{array}$ & SF (APM) & $\frac{3}{(9,20 \text { e } 24-28 / 05 / 94)}$ \\
\hline $\begin{array}{l}\text { Junho/94 } \\
27-28 / 06 / 94\end{array}$ & SpoF (APM) & $\begin{array}{c}4 \\
(4,7-8,22 \text { e } 26 / 0694)\end{array}$ \\
\hline $\begin{array}{l}\text { Julho/94 } \\
26-27 / 07 / 94\end{array}$ & ATAS & $\begin{array}{c}3 \\
(3,7-8,22-23 / 0794) \\
\end{array}$ \\
\hline $\begin{array}{l}\text { Agosto/94 } \\
23-24 / 08 / 94\end{array}$ & SF (APM) & $\begin{array}{c}4 \\
(3,10,16,22-23 / 08 / 94)\end{array}$ \\
\hline $\begin{array}{l}\text { Setembro/ } 94 \\
20-21 / 09 / 94\end{array}$ & ATAS & $\begin{array}{c}3 \\
(3,7-8,15 / 09 / 94) \\
\end{array}$ \\
\hline $\begin{array}{l}\text { Outubro/94 } \\
20-21 / 10 / 94\end{array}$ & SF (APM) & $\begin{array}{c}5 \\
(26-27 / 09,3,10,13-14,20 / 1094)\end{array}$ \\
\hline $\begin{array}{l}\text { Novembro/94 } \\
22-23 / 11 / 94\end{array}$ & ATAS & $\begin{array}{c}5 \\
(21-26 / 10,2,7,9-10,18 / 11 / 94)\end{array}$ \\
\hline $\begin{array}{l}\text { Dezembro/94 } \\
20-21 / 12 / 94\end{array}$ & ATAS & $\begin{array}{c}3 \\
(30 / 11,4-5,18 / 12 / 94) \\
\end{array}$ \\
\hline $\begin{array}{l}\text { Janeiro/95 } \\
18-19 / 01 / 95\end{array}$ & $\begin{array}{l}\text { ATAS p/ Cibratel e SPF (APM) p/ Ita- } \\
\text { Suaräo }\end{array}$ & $(23,28-31 / 12 / 94,3,6-10,12,19 / 01 / 95)$ \\
\hline $\begin{array}{l}\text { Fevereiro/95 } \\
16-17 / 02 / 95\end{array}$ & ATAS & $\begin{array}{c}5 \\
(22,26,29 / 01,3-4,10 / 02 / 95) \\
\end{array}$ \\
\hline $\begin{array}{l}\text { Marco/95 } \\
30-31 / 03 / 95\end{array}$ & ATAS & $\begin{array}{c}7 \\
(19 / 02,3,5,10,15,19,24 / 03 / 95)\end{array}$ \\
\hline $\begin{array}{l}\text { Abril/95 } \\
18-19 / 04 / 95\end{array}$ & ATAS & $\begin{array}{c}2 \\
(2,12 / 04 / 95) \\
\end{array}$ \\
\hline $\begin{array}{l}\text { Maio/95 } \\
15-16 / 05 / 95\end{array}$ & ATAS & $\begin{array}{c}3 \\
(20-21 / 04,2-3,7-8 / 05 / 95)\end{array}$ \\
\hline
\end{tabular}

Legenda: ATAS - dominio do Anticiclone Tropical Atlântico, SF (APM) - sistema frontal oriundo de açào do Anticiclone Polar Migratónio, SPF (APM) - sistema pré-frontal oriundo da do APM e SpoF (APM) - sistema pós-frontal oriundo da aço da APM. 
Tabela 2. Dados de observação de direção de incidência, altura e período das ondas durante os monitoramentos.

\begin{tabular}{|c|c|c|c|c|c|c|c|}
\hline \multicolumn{2}{|c|}{ PRAIA } & \multicolumn{3}{|c|}{ CIBRATEL } & \multicolumn{3}{|c|}{ ITANHAÉM - SUARÃO } \\
\hline Ano/mês & Dia & Direção & $\begin{array}{c}\text { Altura } \\
\text { máxima (m) }\end{array}$ & $\begin{array}{l}\text { Período } \\
\text { (seg.) }\end{array}$ & Direçāo & $\begin{array}{l}\text { Altura máxima } \\
\text { (m) }\end{array}$ & $\begin{array}{c}\text { Período } \\
\text { (seg.) }\end{array}$ \\
\hline \multirow[t]{2}{*}{ Abr/94 } & 27 & $\mathrm{NE}$ & 0.5 & 6.4 & & & \\
\hline & 28 & & & & $\mathrm{NE}$ & 0.5 & 7.4 \\
\hline \multirow[t]{2}{*}{ Mai/94 } & 28 & $\mathrm{NE}$ & 1.0 & 6.6 & & & \\
\hline & 28 & & & & SE & 0.8 & 6.6 \\
\hline \multirow[t]{2}{*}{ Jun/94 } & 27 & SSE & 0.5 & 8.9 & & & \\
\hline & 28 & & & & $\mathrm{E} / \mathrm{SE}$ & 1.5 & 9.5 \\
\hline \multirow[t]{2}{*}{$\mathrm{Ju} \mathbf{u} / 94$} & 26 & $\mathrm{NE}$ & 0.5 & 6.3 & & & \\
\hline & 27 & & & & NE & 0.5 & 8.2 \\
\hline \multirow[t]{2}{*}{ Ago/94 } & 23 & SE & 1.0 & 7.7 & & & \\
\hline & 24 & & & & SE & 1.0 & 5.5 \\
\hline \multirow[t]{2}{*}{ Set/94 } & 20 & $\mathrm{NE}$ & 0.5 & 9.1 & & & \\
\hline & 21 & & & & NE & 0.7 & 7.8 \\
\hline \multirow[t]{2}{*}{ Out/94 } & 20 & $\mathrm{E} / \mathrm{SE}$ & 0.5 & 7.0 & & & \\
\hline & 21 & & & & $\mathrm{NE}$ & 0.5 & 7.7 \\
\hline \multirow[t]{2}{*}{ Nov/94 } & 22 & $\mathrm{SE}$ & 1.0 & 8.7 & & : & \\
\hline & 23 & & & & $\mathrm{SE} / \mathrm{E}$ & 1.0 & 7.9 \\
\hline \multirow[t]{2}{*}{ Dez/94 } & 20 & NE & 1.0 & 7.2 & & . & \\
\hline & 21 & & & & $\mathrm{NE}$ & 0.5 & 10.0 \\
\hline \multirow[t]{2}{*}{$\operatorname{Jan} / 95$} & 18 & $\mathrm{E} / \mathrm{NE}$ & 0.5 & 7.3 & & & \\
\hline & 19 & & & & $\mathrm{~S} / \mathrm{SE}$ & 1.0 & 8.3 \\
\hline \multirow[t]{2}{*}{$\mathrm{Fev} / 95$} & 16 & NE & 1.0 & 10.5 & & & \\
\hline & 17 & & & & E/NE & 0.5 & 7.3 \\
\hline \multirow[t]{2}{*}{ Mar/95 } & 30 & NE & 1.0 & 10.6 & & & \\
\hline & 31 & & & & $\mathrm{E} / \mathrm{SE}$ & 1.0 & 7.1 \\
\hline \multirow[t]{2}{*}{$\mathrm{Abr} / 95$} & 18 & NE & 0.5 & 11.3 & & & \\
\hline & 19 & & & & E & 0.5 & 8.5 \\
\hline \multirow[t]{2}{*}{ Mai/95 } & 15 & $\mathrm{NE}$ & 0.5 & 9.3 & & & \\
\hline & 16 & & & & $\mathrm{E} / \mathrm{NE}$ & 1.0 & 11.5 \\
\hline
\end{tabular}

Os sistemas frontais costumam atuar sobre o litoral paulista com diferentes intensidades sendo que alguns deles interrompem seu deslocamento permanecendo estacionários como aqueles entre os dias 28 - 31/12/94 (na altura de Cananéia), dias 6 a 10/01/95 (na altura de Santos) e nos dias 3 e 4 /02/95 (na altura de Ubatuba). Sistemas de frente quente atuaram neste período no litoral paulista, deslocando-se rumo ao sul do país, nos dias $12 / 01 \mathrm{e}$ 10/02/95. A estes sistemas frontais quentes estiveram associados às maiores pluviosidades medidas, chegando a atingir marcas de $60 \mathrm{~mm}$ de chuva em um único dia.

A atuação de sistemas frontais, com massas de ar polar associadas, foi monitorada em ambas as praias nos meses de maio, agosto e outubro de 1994, entretanto, estes sistemas frontais, oriundos do APM, variaram quanto as suas características de atuação na área de estudo. $\mathrm{O}$ sistema frontal monitorado em maio/94 esteve estacionário na altura de Iguape (SP) entre os dias 24 a 28/05/94. O sistema frontal monitorado em agosto/94 influenciou a área de estudo por cerca de 3 dias ( 22 a 24/08), trazendo consigo uma massa de ar polar de forte intensidade. $\mathrm{O}$ monitoramento de outubro/94 foi efetuado sob frente fria estacionária na altura de Santos (SP) entre os dias 20 a 26/10/94.

Os sistemas frontais, na região de Itanhaém, foram caracterizados por valores de temperatura $\mathrm{e}$ pressão abaixo das médias mensais destes parâmetros. A temperatura média nos dias dos monitoramentos de maio e outubro/94 foi $18^{\circ} \mathrm{C}$ (quando a temperatura média entre os levantamentos ficou em $25^{\circ} \mathrm{C}$ ) e a do dia do monitoramento de agosto/94 em $14^{\circ} \mathrm{C}$ (sendo a média entre os levantamentos de $18^{\circ} \mathrm{C}$ ). $\mathrm{O}$ valor médio da pressão atmosférica nos intervalos entre os monitoramentos de abril - maio e setembro - outubro de 1994 foi de $762 \mathrm{mmHg}$ e o de julho - agosto de 1994 foi de 765,5 mmHg. O valor médio da pressão nos dias de monitoramento foram: $761,2 \mathrm{mmHg}$ (maio/94), $764,9 \mathrm{mmHg}$ (agosto/94) e $758 \mathrm{mmHg}$ (outubro/94). 
$\mathrm{O}$ vento era oriundo dos quadrantes SE/SSE/S. O tempo em geral apresentou-se nublado e/ou chuvoso.

A precipitação foi marcada por chuvas de longa duração (mais do que duas horas), com intensidade fraca (até $10 \mathrm{~mm} / \mathrm{dia}$ em maio e agosto/ 94) a moderada (10-20 mm/dia em outubro/94). As médias mensais de pluviosidade entre os monitoramentos de julho-agosto/94 e setembro-outubro/94 foram de $70 \mathrm{~mm}$. A média entre os levantamentos de julho-agosto $/ 94$ foi de $40 \mathrm{~mm}$. Todos estes períodos, quando confrontados com a curva normal de chuva, apresentaram desvio negativo, sendo estes respectivamente de: $60 \mathrm{~mm}, 40 \mathrm{~mm}$ e $75 \mathrm{~mm}$.

O monitoramento efetuado em junho/94, foi o único efetuado sob condições de pós-frontal, ou seja, foi efetuado dois dias após a passagem de um sistema frontal (dia 25/06) que já havia sido precedido por outro três dias antes (dia 22/06). O sistema de pós-frontal apresentou valores de pressão e temperatura em ascensão, sendo que, nos dias de monitoramento, a temperatura era de $18^{\circ} \mathrm{C}$ (no dia anterior ao início da medição era de $16^{\circ} \mathrm{C}$ ) e a pressão atmosférica era $768,4 \mathrm{mmHg}$ (no dia anterior foi de $763,8 \mathrm{mmHg}$ ). Nos dias do monitoramento, não houve precipitação pluviométrica, porém o intervalo entre os levantamentos de maio junho/94 apresentou média de $100 \mathrm{~mm}$ de chuva com desvio positivo de $10 \mathrm{~mm}$ sob a curva normal de chuva. Os ventos dominantes eram oriundos de $\mathrm{E} / \mathrm{ENE} / \mathrm{NE}$. As ondas incidentes eram provenientes de ENE com amplitudes entre 0,5 a 1 metro e períodos entre 8,9 a 9,6 segundos.

A praia de Cibratel apresentou, sob ação do ATAS, tendência à deposição, exceto no trecho praial junto à desembocadura do Rio Piaçaguera, onde houve erosão da face praial. Já sob ação dos sistemas frontais, a praia apresentou comportamento inverso àquele visto sob o ATAS, com tendência generalizada à erosão, exceto, mais uma vez, no trecho praial junto à desembocadura do Rio Piaçaguera, onde houve deposição (Fig. 4). Neste mesmo trecho da praia houve, a partir de fevereiro/95, a ação de erosão fluvial na pós-praia e face praial, devido a mudança do curso do rio. Esta situação perdurou até o final do monitoramento, em maio/95 (Figs 5a e 5b).

A foz do Rio Piaçaguera mostrou, sob a ação do ATAS, sua desembocadura voltada para $\mathrm{S} / \mathrm{SW}$. Já sob a incidência das ondas do quadrante sul, vigente na passagem dos sistemas frontais, a desembocadura do rio deslocou-se para $\mathrm{E}$, em direção à Pedra dos Jesuítas (Figs 6a e 6b).

A Praia de Itanhaém-Suarão apresentou três segmentos com comportamentos distintos ao longo do monitoramento, sendo o primeiro localizado entre a desembocadura do Rio Itanhaém até cerca de 100 metros de distância desta, o segundo englobou o trecho entre 100 a 350 metros da foz do rio e o terceiro abrangeu o trecho entre 350 a 4500 metros da desembocadura do rio.

Sob o domínio do ATAS, a porção da praia a 100 metros da desembocadura do Rio Itanhaém, mais próxima da linha d'água (cerca de 20 metros de distância do início do perfil) tendeu a apresentar erosão ao contrário do período sob o domínio dos sistemas frontais quando houve tendência à deposição (Fig. 7). A face praial superior apresentou acúmulo de sedimentos, muitas vezes trazidos pelo vento. Houve também neste período, uma pequena progradação deste trecho praial entre abril a outubro/94 e o recuo deste trecho entre novembro/94 e maio/95.

O trecho da praia situado a cerca de $300-$ 350 metros da foz do rio apresentou comportamento bastante irregular, aparentemente não controlado pelas condições meteorológicas. $\mathrm{O}$ processo erosivo foi predominante até setembro/94 com a erosão total do perfil em outubro/94 (Fig. 8a). Uma recuperação deste trecho da praia foi notada, entre janeiro e maio/95, porém a mesma foi descontínua, havendo eventuais retrocessos neste processo (Fig. $8 \mathrm{~b}$ ). Neste mesmo trecho, houve o afloramento parcial de um banco arenoso em formato de "meia lua" (voltado para NE) na antepraia em abril/94 e maio/95.

Já o segmento praial mais distal da desembocadura foi o que menos refletiu as diferenças entre as intensidades de sistemas frontais. De um modo geral, o segmento praial entre 1000 e 3200 metros da foz do rio apresentou, sob ação de sistemas frontais, erosão na parte superior da face praial e deposição próxima à linha d'água. Já sob ação do ATAS foi verificado o comportamento oposto ao anterior. Em outubro, o sistema estacionário em Santos originou ondas provenientes de NE, resultando em uma morfologia da face praial típica de ATAS (Fig. 9).

A praia de Itanhaém-Suarão, sob condições de pré-frontal, teve a morfologia da face praial bastante similar àquela vista sob influência de ATAS diferindo desta pelo quadrante de incidência de ondas e pela tendência generalizada de deposição ao longo da praia.

Por fim, sob ação de sistema pós-frontal, ambas as praias apresentaram tendência erosiva, exceto na porção mais próxima ao Morro do Paranambuco (Praia de Cibratel) e alguns pontos localizados da Praia Itanhaém-Suarão onde predominaram processos deposicionais.

Variações dos parâmetros meteorológicos (sobretudo pluviosidade) e oceanográficos (ondas), resultaram em comportamentos praiais distintos ao 
padrão, anteriormente descrito. Na Praia de Cibratel, os monitoramentos efetuados em julho/94 e fevereiro/95 no trecho próximo ao Morro do Paranambuco, mostraram que a morfologia praial ainda não havia se recuperado da influência dos eventos de frente do mês, mesmo após 2 dias da passagem do último destes sistemas (Fig. 10).
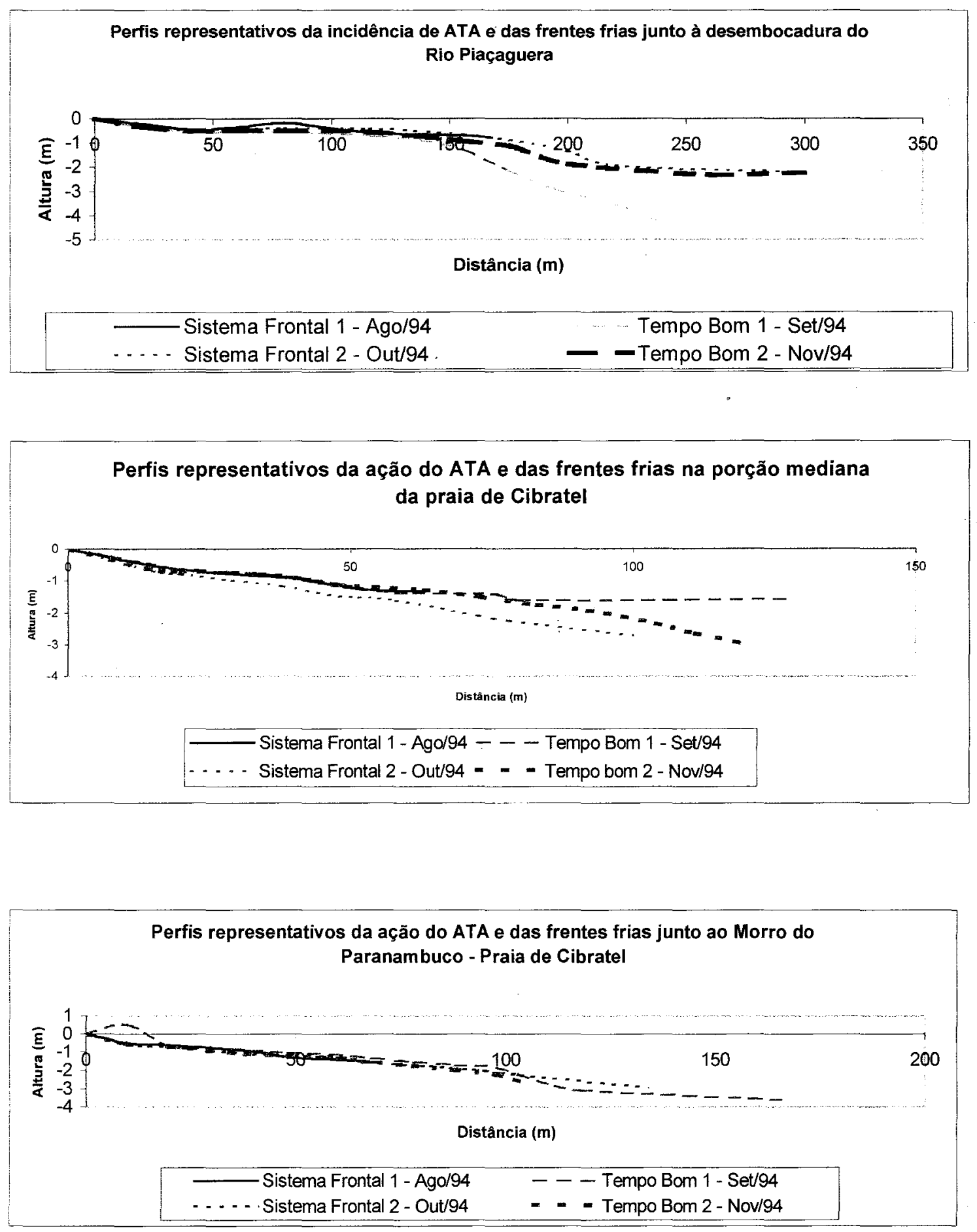

Fig. 4. Perfis representativos da Praia de Cibratel. 

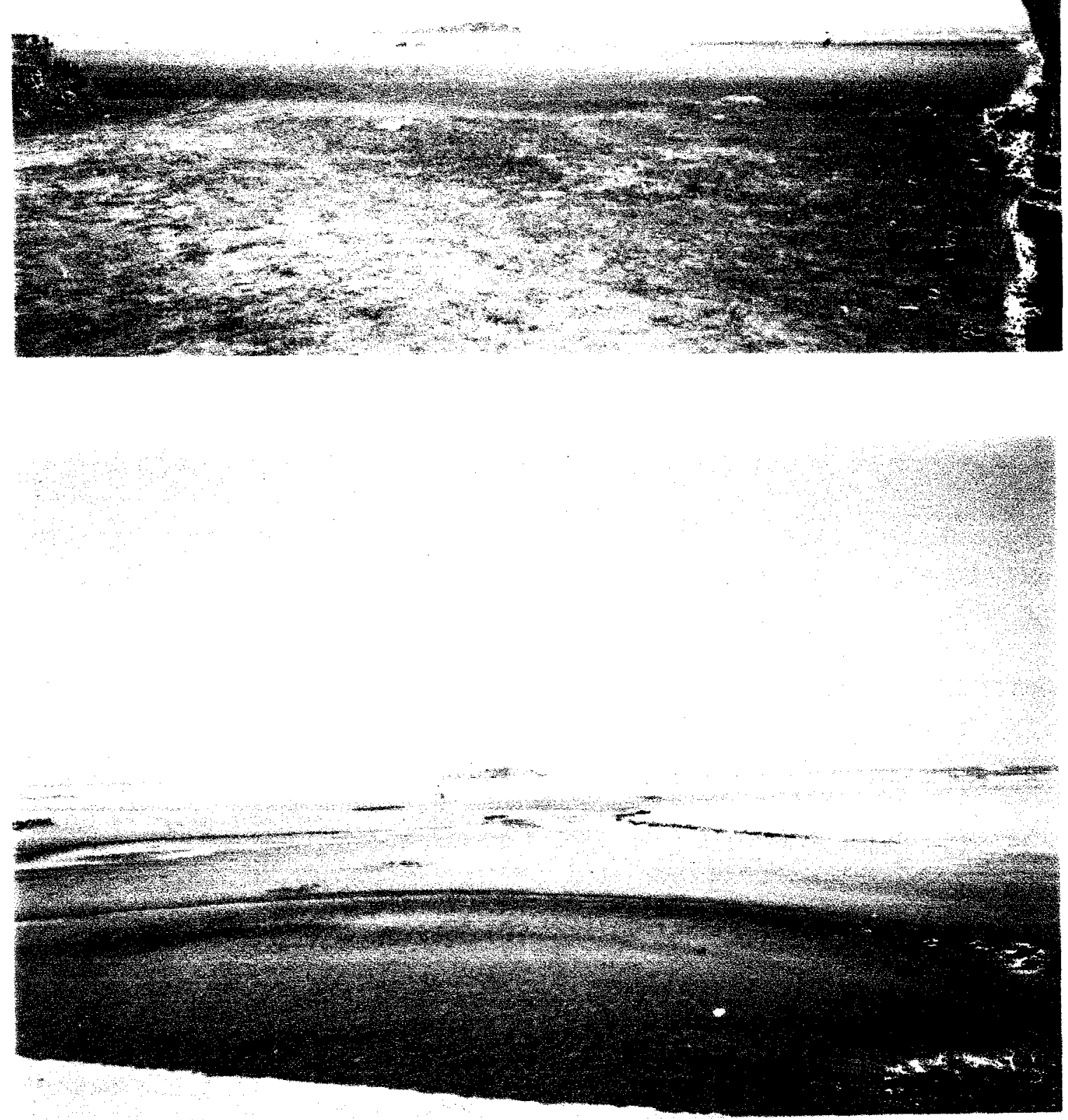

Fig. 5. Vista do perfil P11 em abril/94 (5a) e em fevereiro/95 (5b), com o deslocamento do curso do Rio Piaçaguera. 


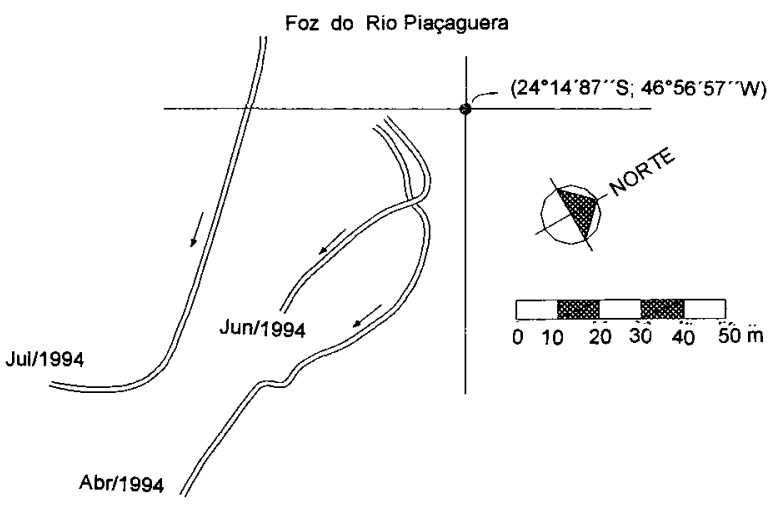

Foz do Rio Piaçaguera

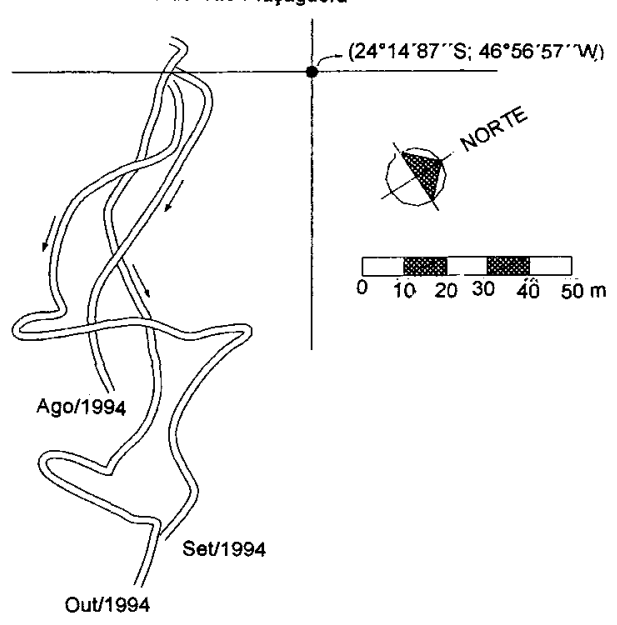

Fig. 6a. Desembocadura do Rio Piaçaguera monitorada entre abril e outubro/94. O acompanhamento do rio foi efetuado a partir do ponto inicial do perfil P11. As setas indicam o curso do rio na praia. A desembocadura foi monitorada até a linha d'água vigente.

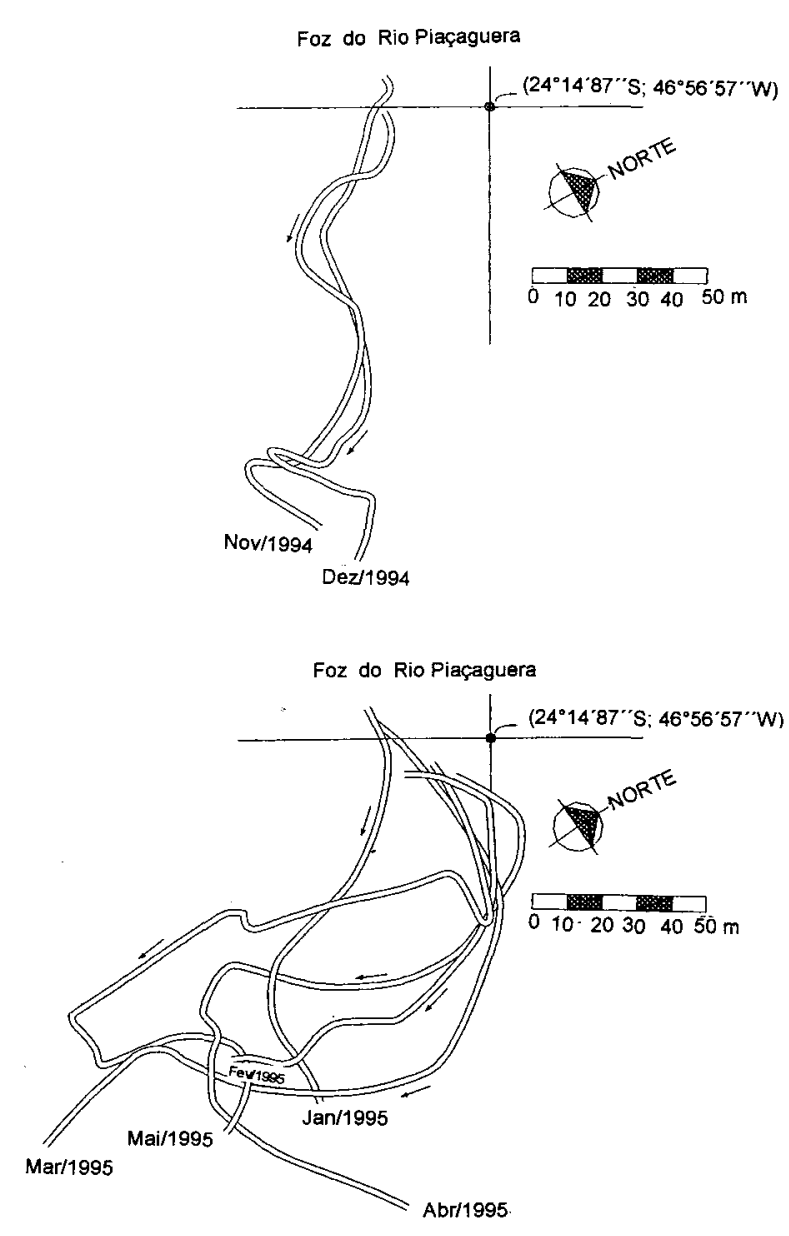

Fig. 6b. Desembocadura do Rio Piaçaguera monitorada entre novembro/94 e maio/95. $O$ acompanhamento do rio foi efetuado a partir do ponto inicial do perfil P11. As setas indicam o curso do rio na praia. A desembocadura foi monitorada até a linha d'água vigente.

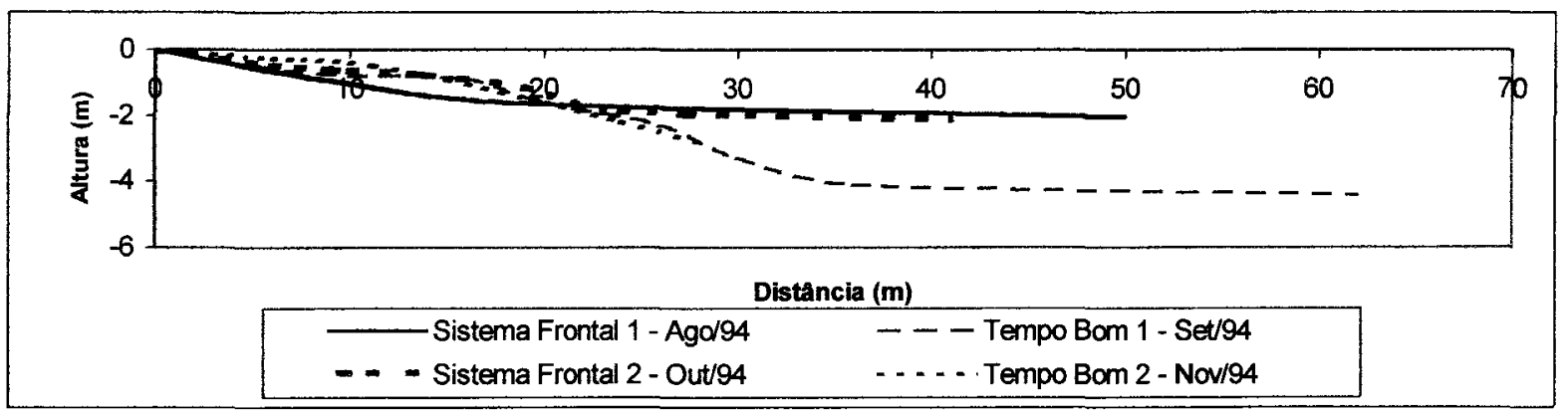

Fig. 7. Perfil representativo do trecho à 100 metros da foz do Rio Itanhaém, Praia de Itanhaém-Suarão. 

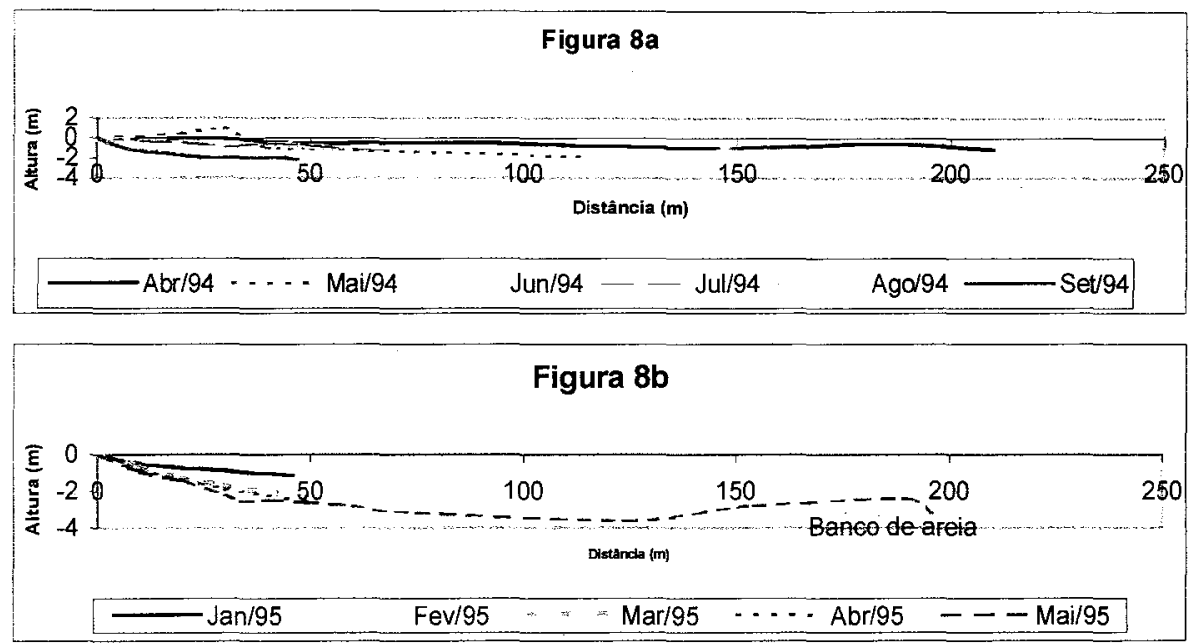

Fig. 8. Perfil representativo do treco à 350 metros da foz do Rio Itanhaém. A Figura 8 a mostra um processo erosivo entre abril e outubro/94 e Figura $8 \mathrm{~b}$ mostra um processo de recuperação (não contínuo) do perfil praial.
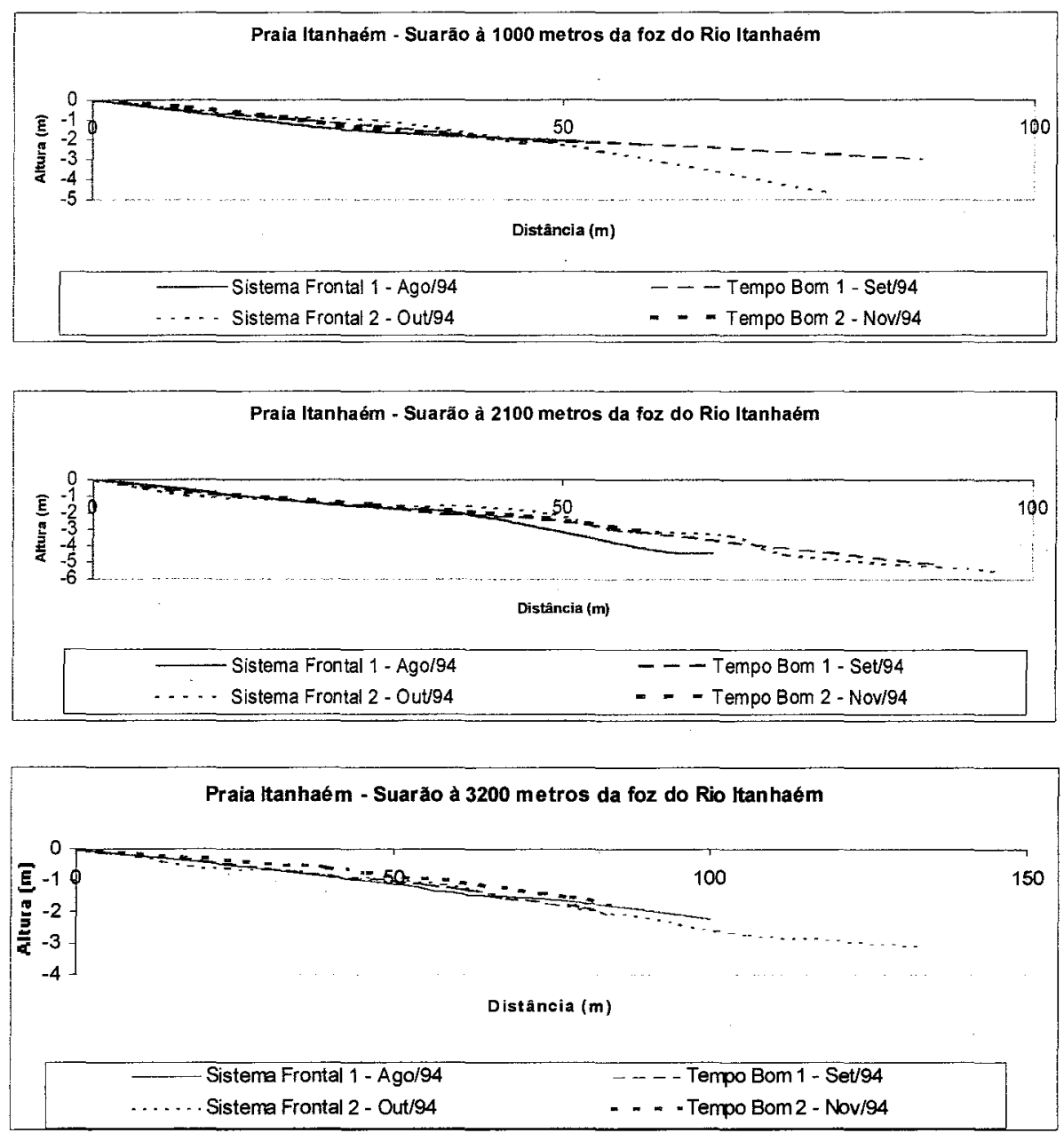

Fig. 9. Perfis representativos do segmento praial entre 1000 e 3200 metros da desembocadura da foz do Rio Itanhaém, na Praia de Itanhaém-Suarão. 


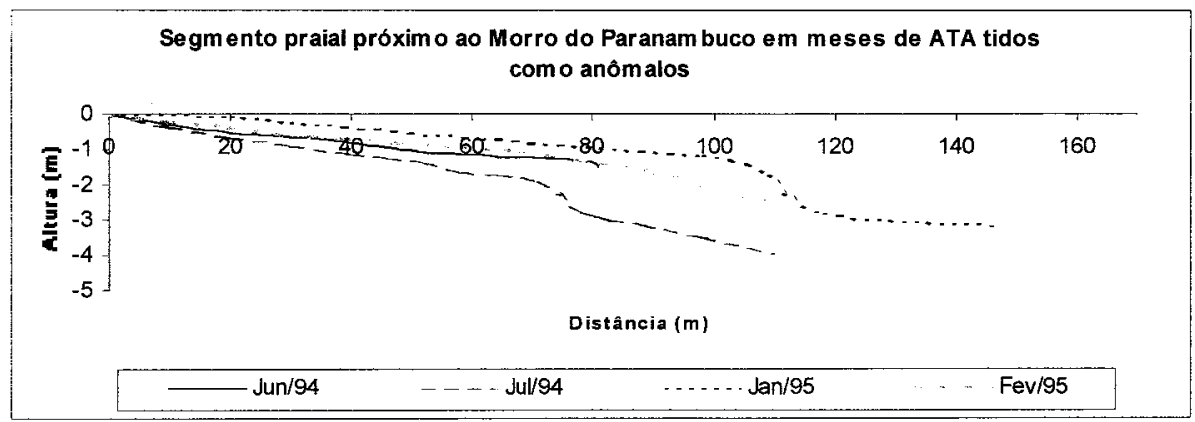

Fig. 10. Segmento da praia de Cibratel próximo ao Morro do Pernambuco onde houve lentidão na recuperação do perfil praial.

$\mathrm{Na}$ Praia de Itanhaém-Suarão, no levantamento efetuado em dezembro/94, houve a incidência de ondas de NE com período de 10 segundos e uma erosão generalizada da face praial. No período entre os monitoramentos de novembro e dezembro/94, houve a passagem de 2 sistemas frontais e uma linha de instabilidade que atuou 4 dias antes da etapa de monitoramento.

Este fenômeno de erosão da face praial foi temporário, pois no levantamento seguinte (janeiro/95), mesmo após a ação de 6 sistemas frontais e aumento da precipitação na área, houve deposição generalizada ào longo da praia. Nesta mesma praia, foi visto no monitoramento de fevereiro/95 uma maior tendência à erosão. Entre os levantamentos, houve represamento dos sistemas frontais no litoral paulista e o aumento significativo da quantidade de chuva.

A estimativa das variações do volume sedimentar para cada perfil monitorado está apresentada na Tabela 3.

As amostras de sedimentos coletadas concomitantemente à realização dos perfis praiais mostraram que os sedimentos existentes nas duas praias apresentaram características distintas entre si, exceto quanto ao teor de carbonato biodetrítico, que os coloca, segundo a classificação de Larsonneur et al. (1982), como sedimentos litoclásticos.

A Praia de Cibratel apresentou, ao longo de todo o monitoramento, sedimento arenoso muito fino, muito bem selecionado, aproximadamente simétrico e com curtose tendendo a leptocúrtica. A análise textural mostrou que estes sedimentos eram polidos, arredondados e esféricos, compostos basicamente por quartzos e secundariamente por biotita, muscovita, opacos e fragmentos biogênicos. Apenas na porção próxima ao Morro do Paranambuco, os sedimentos eram mesocúrticos, mais angulosos e com maior porcentagem de opacos e muscovita. O entorno da desembocadura do Rio Piaçaguera também apresentou um enriquecimento em muscovita.

A Praia de Itanhaém-Suarão apresentou sedimentos arenosos com moda predominantemente fina (localmente moda areia média), bem a moderadamente selecionados, polidos, arredondados e esféricos (embora menos que aqueles vistos em Cibratel). Os parâmetros assimetria e curtose apresentaram valores muito variáveis ao longo desta praia. Mineralogicamente, estes sedimentos apresentaram composição quartzosa e secundariamente, eram compostos por muscovita, hornblenda, biotita, opacos e fragmentos biogênicos, além de granada e turmalina em pontos localizados. Os grãos mais grossos e imaturos (tanto texturalmente quanto mineralogicamente) estavam situados em adjacências da desembocadura do Rio Itanhaém, sobretudo no período entre abril a outubro/94 e fevereiro a maio/95.

Tabela 3. Estimativa da variação de volume de sedimentos nos perfis praiais ao longo do monitoramento $\left(\mathrm{em}^{3}\right)$.

\begin{tabular}{|c|c|c|c|c|c|c|c|c|}
\hline Praias & \multicolumn{5}{|c|}{ Praia Itanhaém-Suarão } & \multicolumn{3}{c|}{ Praia Cibratel } \\
\hline Perfis & P4 & P5 & P6 & P7 & P8 & P9 & P10 & P11 \\
\hline Valor Total & $-45,19$ & $-143,3$ & $-78,93$ & $-311,02$ & $-27,13$ & 5,57 & 83,91 & 32,1 \\
\hline
\end{tabular}


O mapa batimétrico da zona submersa adjacente à área de estudo mostrou um relevo suave, com declividade média de $0,18^{\circ}$ (Giannini, 1987). As isóbatas mostravam-se espaçadas, paralelas entre si e com a linha de costa (exceto no trecho defronte ao Morro do Paranambuco), com trechos de maior declividade entre as profundidades de 5 a 7 metros defronte à foz do Rio Itanhaém e entre 4 a 9 metros defronte à Praia Itanhaém-Suarão.

Já a granulometria dos sedimentos de fundo apresentou um resultado muito similar àquele encontrado na Praia de Cibratel quanto à descrição morfoscópica e mineralógica e parâmetros estatísticos como diâmetro médio (areia muito fina), grau de seleção (muito bem selecionado) e curtose (leptocúrtica). A exceção ficou restrita a um trecho localizado próximo à desembocadura do Rio Itanhaém, onde os sedimentos apresentaram um grau de seleção moderado. O parâmetro assimetria foi o único que diferiu da área emersa, apresentando assimetria simétrica a positiva. Em termos de teor de carbonato biodetrítico, os sedimentos foram classificados como litoclásticos (segundo a classificação de Larsonneur et al.,1982).

\section{Discussão}

Os segmentos praiais estudados revelaram o predomínio temporal do ATAS sobre as condições de atuação dos sistemas frontais, porém estes últimos foram mais efetivos, caracterizando-se por um modelamento mais eficiente da morfologia das praias.

A batimetria efetuada na antepraia mostrou uma morfologia suave, que permite a livre atuação das ondas, favorecendo a retirada de finos (siltes e/ou argilas) oriundos das drenagens locais. Este fato é corroborado pela presença de sedimentos arenosos na faixa submersa estudada.

A praia de Cibratel apresentou, em sua porção mediana, tendência de deposição devido ao predomínio de ondas NE provenientes do ATAS, com ganho sedimentar de $83 \mathrm{~m}^{3}$ ao longo do período monitorado e variação máxima de 2 metros na face praial. Os eventos erosivos verificados neste trecho praial puderam ser explicados pela ação de ondas provenientes do quadrante sul (sistemas frontais) ou de NE quando oriundas de sistemas pós-frontais.

As áreas próximas ao Embasamento Cristalino (desembocadura do Rio Piaçaguera $\mathrm{e}$ Morro do Paranambuco) apresentaram comportamentos diferenciados aos da porção mediana da praia.

O trecho próximo ao Morro do Paranambuco, devido provavelmente à presença do
Embasamento Cristalino, sofreu erosão somente em casos de atuação de sistemas frontais, com variação vertical máxima de 3 metros na face praial. A ação das ondas de NE/E (oriundas do ATAS e de sistemas pós-frontais) juntamente com o processo de difração e refração das ondas no Morro do Paranambuco foi suficiente para a recuperação deste segmento, com pequeno ganho sedimentar ao longo de todo o período $\left(5,57 \mathrm{~m}^{3}\right)$ embora existam eventos em que a recuperação destes perfis seja mais lenta (como visto em novembro/94 e fevereiro/95). Contribuições sedimentares provenientes do próprio Embasamento Cristalino bem como de esporádicas contribuições do Rio Itanhaém podem ter influído na diferenciação das características sedimentológicas deste trecho em relação ao restante desta praia.

O trecho da praia junto ao Rio Piaçaguera, sob ação de sistemas frontais, sofreu progradação devido à sombra de deposição criada pela Pedra dos Jesuitas associada ao "efeito molhe hidráulico" que a migração da foz do Rio Piaçaguera causou quando migrou para leste. Já a ação das ondas oriundas de NE (ATAS e sistemas pós-frontais), juntamente com a ação fluvial, ocasionou uma tendência erosiva que não foi suficiente para reverter a progradação deste ponto até o mês de janeiro/95. Por sua vez, o balanço sedimentar deste trecho mostrou perda de sedimentos ao longo do trecho monitorado $\left(-32,1 \mathrm{~m}^{3}\right)$ que pode ser explicado pela erosão fluvial do rio Piaçaguera ao longo de toda a face praial. A variação vertical máxima nesta face praial foi de aproximadamente de 4 metros. $O$ enriquecimento de muscovita verificado neste ponto pôde ser explicado como contribuição do próprio rio em eventos de maior pluviosidade.

Não foi visto em nenhum dos monitoramentos, algum indício de erosão mais acentuado como escarpas de praia relacionadas à passagem de sistemas frontais como aquelas notificadas por Calliari et al. (1996).

O ganho sedimentar na porção mediana e o alargamento da praia rumo nordeste, este último verificado também em fotografias aéreas, sugerem que $o$ transporte de sedimentos é feito preferencialmente pela ação da deriva litorânea rumo $\mathrm{NE}$, atuante quando da ação de sistemas frontais (ondas S/SE/ESSE), concordando com Calliari et al. (op. cit.) que afirmaram que a passagem de sistemas frontais ocasiona com maior remobilização de sedimentos. Por sua vez, a ação das ondas NE (oriundas da ação $\cdot$ do ATAS) condicionou a existência de correntes rumo SW que erodiram o trecho da desembocadura do Rio Piaçaguera.

Quando comparados entre si os trechos mais próximos ao Embasamento Cristalino, notou-se que as fases erosivas em um extremo correspondiam as fases construtivas no outro. Este tipo de mecanismo é 
bastante comum ao longo da costa brasileira tendo sido descrita por Farias et al. (1985) na praia da Armação (BA) e Albino (1993) na praia de Macaé $(\mathrm{RJ})$. Ambos os autores atribuíram este fato à ação e freqüência de frentes frias que atingem a costa.

Já o estudo da dinâmica sedimentar da praia Itanhaém-Suarão mostrou que a praia sofreu influência da desembocadura do Rio Itanhaém, sendo esta, porém, diferenciada de acordo com a distância entre o trechos estudados e a foz do rio. Esta variabilidade da influência fluvial na praia foi monitorado sob a ação de ATAS, sistemas frontais e de pós-frontal, sendo que no caso de sistemas préfrontais, o monitoramento foi efetuado no princípio de atuação das ondas SSE, quando o padrão de incidência deste trem de ondas não haviam tido, ainda, tempo suficiente para alterar a morfologia praial.

De uma forma geral, o estudo das fotografias aéreas, os dados granulométricos e os de composição mineralógica mostraram a maior efetividade da deriva litorânea rumo NE, denotando maior influência dos sistemas frontais sob $o$ transporte dos sedimentos e a morfologia da praia. Em caso de ação de deriva longitudinal de sedimentos mais efetiva (como aquela verificada sob ação de ATAS no monitoramento efetuado em dezembro/94) ocorreu a erosão generalizada ao longo de toda a praia, porém este fenômeno foi de curta duração sendo que a praia teve um rápido ganho sedimentar no período seguinte.

$O$ trecho mais próximo da foz do Rio Itanhaém apresentou, sob ação de ATAS e de pósfrontal, tendência à perda de sedimentos ao longo do monitoramento $\left(-27,13 \mathrm{~m}^{3}\right)$, variação vertical máxima de 5 metros e presença de sedimentos finos a médios e com mineralogia similar àquela encontrada na Praia de Cibratel. Já sob a atuação de sistemas frontais, este trecho sofreu deposição, sendo os sedimentos de maior moda (areia média) e com maior presença de minerais típicos das serras adjacentes (granada).

O trecho situado à cerca de $300-350$ metros à nordeste da desembocadura do Rio Itanhaém, foi o trecho em que houve a maior perda sedimentar ao longo do monitoramento $\left(-311,02 \mathrm{~m}^{3}\right)$ e variação máxima de 4 metros na face praial. Porém, o que mais marcante neste trecho foi a sedimentação e o comportamento morfológico da face praial. No período entre abril a outubro/94, este segmento praial sofreu retrogradação até a erosão máxima em outubro/94. De novembro/94 a maio/95, este trecho da praia passou a sofrer progradação (embora não contínua), apresentando em maio/95, uma morfologia relativamente similar àquela vista em abril/94 para este ponto. O afloramento parcial do banco arenoso na antepraia mostrou o armazenamento de material sedimentar neste trecho praial, indicando baixa ação da deriva longitudinal na redistribuição destes sedimentos. A direção em que estava voltado o banco arenoso, indicou a maior influência da ação de deriva longitudinal para NE.

O trecho mais próximo à desembocadura e o trecho a cerca de 300 - 350 metros da foz apresentaram comportamentos opostos entre si, quando comparados entre si (sobretudo no período entre abril a outubro/94), devido a maior influência fluvial neste segmento da praia. $\mathrm{O}$ primeiro trecho, por estar mais próximo da foz, esteve mais protegido da ação dos sistemas frontais por um provável molhe hidráulico do Rio Itanhaém e recebeu um incremento dos sedimentos carreados pelo rio, sobretudo em épocas de maior pluviosidade. $O$ segundo trecho pareceu sofrer ação de processos fluviais e marinhos, sendo que em épocas de menor pluviosidade, este ponto sofreu retrogradação provavelmente devido ao menor aporte de sedimentos. Com o aumento do índice de chuvas, este trecho praial recuperou-se.

Como ambos os trechos possuiam a sua morfologia e sedimentação mais dependentes da ação fluvial, foram reunidos em único compartimento aqui denominado de Itanhaém.

Já o restante da praia foi denominado de Compartimento Suarão e este apresentou um comportamento morfológico praial intermediário entre a sedimentação das outras praias. Houve tendência deposicional durante a ação do ATAS e de sistemas frontais estacionados na altura de Santos (ondas de NE) e ocorreu erosão quando as ondas são oriundas de $\mathrm{S}$ (sistemas frontais), com variações máximas verticais de 4 metros. Por outro lado, os dados de diâmetro médio, grau de seleção e composição mineralógica dos sedimentos indicaram uma influência, ainda que pequena, do Rio Itanhaém, o que tornou mais complicada a dinâmica sedimentar costeira deste trecho. $O$ balanço erosivo/ deposicional dos perfis aqui englobados mostraram perda de sedimentos de respectivamente $-78,93 \mathrm{~m}^{3}(\mathrm{P} 6),-143,3 \mathrm{~m}^{3}(\mathrm{P} 5) \mathrm{e}-$ $45,19 \mathrm{~m}^{3}$ (P4).

Esta diferença no balanço sedimentar entre ambas as praias pode ser explicado pela atuação do Rio Itanhaém e pela intensificação do uso e ocupação da praia deste compartimento. Durante todo o tempo de monitoramento, foram efetuadas as construções de quiosques para veranistas, reformas em propriedades com o uso da areia da face praial e de pequenas dunas (que foram totalmente destruídas), construção de muros e de saídas de águas fluviométricas (pequenos córregos) e pluviométricas que desaguavam na face praial. 


\section{Conclusões}

As praias de Itanhaém-Suarão e Cibratel apresentaram dinâmicas sedimentares distintas, sendo estas regidas principalmente pelo padrão de ondas incidentes, que por sua vez foram regidos pelos parâmetros meteorológicos atuantes na região.

Houve, em ambas as praias, o predomínio de erosão sob ação dos sistemas frontais e deposição sob a ação do ATAS e dos sistemas pós-frontais. Exceções ocorrem em alguns trechos como aquele situado em proximidades da foz do Rio Piaçaguera, na praia de Cibratel, devido à presença da própria foz do rio e, também, da Pedra dos Jesuítas. Já na Praia de Itanhaém-Suarão, a exceção ocorreu no trecho situado entre 100 - 350 metros da desembocadura do Rio Itanhaém que teve sua morfologia influenciada principalmente pela ação deste rio.

As principais modificações ocorridas nas praias estiveram associadas à passagem de sistemas frontais, que ocasionariam deriva longitudinal rumo NE. Na Praia de Itanhaém-Suarão foi possível verificar que embora mais eficiente, a corrente rumo $\mathrm{NE}$ não consegue remobilizar todo o material sedimentar que fica armazenado na antepraia sob a forma de bancos arenosos.

Sob a ação da ATAS, os sistemas de ondas incidentes sobre as praias induziram deriva longitudinal rumo SW. Esta deriva mostrou-se mais evidente na remobilização da face praial na Praia de Cibratel, onde erodiu o trecho próximo à foz do Rio Piaçaguera.

A Praia de Cibratel teve sua dinâmica sedimentar regida pela interrelação entre os parâmetros hidrodinâmicos (ondas) e fisiográficos. O processo deposicional nesta praia foi fortemente condicionado pela presença do Embasamento Cristalino. A foz do Rio Piaçaguera, juntamente com a Pedra dos Jesuítas, sob ação de sistemas frontais, exerceu um efeito de barramento auxiliando na progradação do trecho praial em suas adjacências. $\mathrm{O}$ balanço sedimentar desta praia é positivo, com exceção do trecho próximo ao Rio Piaçaguera devido à própria erosão fluvial.

A Praia de Itanhaém-Suarão, por sua vez, apresentou dinâmica sedimentar diferenciada devido a uma influência mais marcante ou incipiente dos processos fluviais sobre a dinâmica costeira e conseqüentemente sobre os mecanismos de sedimentação da região à nordeste do Rio Itanhaém, subdividindo a praia em dois compartimentos: Itanhaém e Suarão.

O Compartimento Itanhaém apresentou dois trechos com comportamentos opostos, sobretudo no período entre abril a outubro/94, culminando com a erosão total do trecho a 300-350 metros da foz em outubro/94. O afloramento parcial de um banco arenoso na antepraia nos meses de abril/94 e maio/95 confirmou a existência de uma ritmicidade na sedimentação deste segmento da praia no período monitorado. Este ciclo de sedimentação do Compartimento Itanhaém pôde ser explicado pela variação da quantidade e intensidade dos sistemas frontais e precipitação pluviométrica. Todos estes parâmetros foram mais freqüentes e/ou intensos no período após outubro/94. O balanço sedimentar deste compartimento foi negativo, sobretudo no trecho entre 300 a 350 metros da desembocadura fluvial.

Já no Compartimento Suarão, a influência fluvial foi notória somente durante a passagem de sistemas frontais. Esta influência aliada ao condicionante antrópico resultou em um mecanismo de sedimentação com balanço sedimentar negativo.

\section{Referências bibliográficas}

Albino, J. 1993. Morfodinâmica e processos de sedimentação das praias da Barra e São José do Barreto - Macaé - RJ. Dissertação de mestrado. Universidade Federal do Rio de Janeiro, Instituto de Geociências. 80p.

Calliari, L. J.; Tozzi, H. M. \& Klein, A. H. da F. 1996. Erosão associada a marés meteorológicas na costa sul-riograndense (COMEMIR/OSNLR). In: CONGRESSO BRASILEIRO DE GEOLOGIA, 39, Salvador, 1996. Salvador, SBG, Anais, 4:430 -434.

DAEE (DEPARTAMENTO DE ÁGUAS E ESGOTOS/SRHSO SECRETARIA DE RECURSOS HÍDRICOS, SANEAMENTO E OBRAS. 1998. Banco de dados pluviométricos do Estado de São Paulo, atualizado até 1997. Cdroom.

Farias, F. F.; Bittencourt, A. C. S. P.; Zanini Jr., A. \& Dominguez, J. M. L. 1985. Variações temporais e espaciais na dinâmica de sedimentação da Praia da Armação Salvador/Ba. Rev. Bras. Geoci., 15(1):48-54.

Giannini, P. C. F. 1987. Sedimentação quaternária na Planície Costeira de Peruíbe-Itanhém (SP). Dissertação de mestrado. Universidade de São Paulo, Instituto de Geociências. 2 v.

Gross, M. G. 1971. Carbon determination. In: Carver, R. E. ed. Procedures in sedimentary petrology. New York, Wiley-Interscience. p.573596. 
INPE. Instituto Nacional de Pesquisas Espaciais. 1994. Climanálise: Boletim de monitoramento e análise climática. 9(4-12).

INPE. Instituto Nacional de Pesquisas Espaciais. 1995. Climanálise: Boletim de monitoramento e análise climática. $10(1-5)$.

King, C. A. M. 1972. Beaches and coasts $2^{\text {nd }}$ ed. London, Edward Arnold, 570p.

Larsonneur, C.; Bouysee, P. \& Aufret, J. P. 1982. The superficial sediments of the English Chanel and its western approaches. Sedimentology, 29(6):851-864.

Mahiques, M. M. de 1987. Considerações sobre os sedimentos de superfície de fundo da Baía de Ilha Grande, Estado do Rio de Janeiro. Dissertação de mestrado. Universidade de São Paulo, Instituto Oceanográfico. 2 v.

Muehe, D. 1996. Geomorfologia costeira. In: Cunha, S. B. \& Guerra, A. J. T. eds Geomorfologia: exercícios, técnicas e aplicações. Rio de Janeiro, Bertrand Brasil. p.191-238.
Sant'Anna Neto, J. L. 1990. Ritmo climático e a gênese das chuvas na zona costeira paulista. Dissertação de mestrado. Universidade de São Paulo, Faculdade de Filosofia, Letras e Ciências Humanas, Departamento de Geografia. 156p.

Suguio, K. 1973. Introdução à sedimentologia. São Paulo, Edgard Blücher. 317p.

Suguio, K. \& Martin, L. 1978. Formações quaternárias marinhas do litoral paulista e sul fluminense (Quaternary marine formations of the State of São Paulo and southern Rio de Janeiro). In: INTERNACIONAL SYMPOSIUM ON COASTAL EVOLUTION IN THE QUATERNARY, São Paulo, 1978. São Paulo, SBG/IGUSP, Special Publication, $\mathrm{n}^{\circ}-1$. 55p.

Tessler, M. G. \& Mahiques, M. M. de 2000. Por uma terminologià sobre os sistemas praiais. In: SIMPÓSIO BRASILEIRO SOBRE PRAIAS ARENOSAS, Itajaí, 2000. Anais. Itajaí, UNIVALI, p.68-69.

(Manuscrito recebido 01 junho de 1999; revisado 03 julho 2000; aceito 07 de dezembro 2000) 